\title{
Albubo Festival as a Tool to Enhance Community Engagement of Buguias, Benguet Residents
}

\author{
Jenalyn P. Oligo \\ Benguet State University, Benguet, Philippines \\ Email: oligojenalyn@gmail.com \\ Jaicelle P. Smith \\ Benguet State University, Benguet, Philippines \\ Email: smithjaicelle@gmail.com \\ Joseph B. Quinto \\ Benguet State University, Benguet, Philippines \\ Corresponding author email: j.quinto@bsu.edu.ph
}

\begin{abstract}
Researchers that have examined the contribution of the Albubo Festival to local development have focused more on its economic impact. Consequently, this study aimed to examine the participation of the residents as well as the effectiveness of the festival itself. The results showed that passive participation (level 2) is the most prevalent. It implies that the residents are interested in having joint effort with the Local Government Unit (LGU) and with the organizers of the cultural festival. The tools to enhance effective community engagement in Albubo Festival were informing decisions, building capacity, and strengthening relationships. The results also revealed that there is an insignificant relationship between the level of participation of Buguias residents on the Albubo Festival and its effectiveness in community engagement. It implies that the level of participation of the residents does not influence the level of effectiveness of the Albubo Festival in community engagement or vice versa. Thus, passive participation, functional participation, participation by consultation, and empowered participation are not related to the effectiveness of the activities such as cultural presentations, Ukob, agricultural trade fair, agri-booth competition, and inter-barangay sports competition held during the celebration.

Keywords---Albubo festival, Buguias residents, community engagement, cultural festival, enhance effective
\end{abstract}

\section{Introduction}

Albubo Festival is the manifestation of the town's indigenous knowledge systems and practices among the residents of Buguias, Benguet, Philippines. Albubo denotes a Kankana-ey term, known as the traditional "bayanihan" practice in the community, which was first celebrated on February 27, 2017. Its annual celebration was institutionalized by Ordinance 3, s. 2013, which declared the celebration of the town fiesta every first Friday of March. Albubo and $u b b o$ are the indigenous practices that the festival aims to achieve (Lacaden, 2017). The word Albubo means contributing and giving without expecting something in return, while the word ubbo means giving something but expecting to have a thing "when the time comes".

It is important to practice and celebrate cultural festival like Albubo Festival because it shapes how participants of a festival relate to each other, how meaning is created through their participation and active involvements, and how powerful the community is if unity is the common objective. One way to achieve bayanihan is for the community to attain effective community engagement within their culture, and have a sense of belongingness towards their cultural practices. Community engagement is a process of collaboratively working towards an issue or event. Its example is the residents and the local government's joint effort towards Albubo Festival. Community 
festivals strengthen the social fabric of the communities in which they take place (Small, 2007). Cultural festivals represent an opportunity for every individual member of a community to come together to socialize, celebrate, and be entertained. Furthermore, festivals not only uphold community engagement among residents but also maintain the preservation and protection of the culture of the local community. Awas (2009), noted that cultural festivals in the region usually take two-fold, one for cultural protection and the other for development (economic) purposes. First, cultural festival can be preserved by passing the tradition through the interaction of the community, involvement of the residents, and community engagement during the celebration. The celebration of cultural festivals creates an opportunity to have cultural awareness among the community. Second, the activities of a cultural festival not only maintain and preserve the culture but also foster and boost the economy. The major reasons for organizing a festival are to promote local products and to improve location's image. Also, it is linked to support tourism activities and programs raising the cultural awareness of every resident (Stankova \& Vassenska, 2015). Through cultural festivals, a town can promote itself, its products, its traditions, and its tourist spots to the local community and to the tourists. With this, it has an enormous role in the economy and in the protection of the culture in a community (Laing, 2018; Lee et al., 2004).

The importance of protecting and maintaining cultures has been recognized by the Philippine law under Republic Act No. 8371. This act provides mechanisms for creating National Commission on Indigenous Peoples, for implementing and establishing guidelines and appropriation of funds. The act encapsulates the rights of the indigenous peoples, where culture is highlighted.

"The states shall respect, recognize and protect the right of ICCs/IPs to serve and protect their culture, traditions and institutions. It shall consider these rights in the formulation and application of national plans and policies (IPR Act of 1997)."

In fact, the Philippine Development Plan (PDP) 2017-2022 emphasizes the importance of the empowerment of the nature of culture. PDP acknowledges that enhancing the social fabric toward a high-trust society entails building better relations for social cohesion among people. In addition, the UN General Assembly's adoption of the UN Declaration on the Rights of the Indigenous Peoples on September 13, 2007 recognized the IP communities of their rights to practice, protect, develop, and maintain cultural practices for cultural enhancement and for their own development. Quoted in full is article 11 of the said Declaration:

\begin{abstract}
"Indigenous peoples have the right to practice and revitalized their cultural traditions and customs. This includes the right to maintain, protect and develop the past, present, and future manifestations of their cultures, such as archeological and historical sites, artifacts, designs, ceremonies, technologies and visual and performing arts and literatures (Article 11, UNDRIP 2007)."
\end{abstract}

Moreover, United Nations Educational Scientific and Cultural Organization (UNESCO) recognized that culture plays a central role in enhancing and sustaining individuals' and communities' quality of life and wellbeing. Undoubtedly, worldwide, festivals and local special events are used as key elements for attaining a common goal, which is a high standard of living. Through the celebration of Bayanihan or Albubo Festival, cultural practices will be maintained. With the IPR Act of 1997, Philippine Development Plan, and international Shultz (2015), (UNESCO) recognitions, it can be guaranteed that culture will be fostered through its development process. Central to this integration then is the role of communication in binding and in bridging the potential opportunities of not only promoting and protecting the culture but also upholds community engagement and participation among the residents. Through a community's collective effort, culture can be nurtured and maintained (Awas, 2009). The challenge of participation and community engagement simply points out that cultural festivals are meant to empower and must never compromise but instead work towards community oneness and cohesion (Makdisi et al., 2011; Minter et al., 2005).

Most of the research studies that examined the contribution of festivals to local development focused more on evaluating its economic impact (O'Sullivan \& Jackson, 2002; Kim et al., 2003). Predominantly, the analysis involves the estimation of the measurement of employment change and income through the celebration of local festivals. However, the study of Choi et al. (2020), argues that the economic impact of the festival itself to the participants is not seriously visible to every participant of the event, and it is not easy to be measured by the organizers (Ryan et al., 2020; Moser \& Pike, 2015). 
Theoretical framework

Participation theory of communication

Participation Theory of Communication by Paolo Mefalopolus describes the community members' kind of participation towards the relevant activities, like festivals, that are held. There are four typologies of the Participation Theory of Communication of Mefalopulos. The first typology is the functional participation. This refers to the residents who are informed about an event's activities and regulations. The second typology is passive participation, where the residents are involved in the planning and execution of an event. The third typology is the participation by consultation. In this, the residents are consulted by the local government officials or facilitators on event-related issues. The fourth typology is the empowered participation; the residents here are not hindered and limited by the facilitators (Zou et al., 2021; Lee \& Lee, 2019).

\section{The engagement triangle}

Effective community engagement is a way of assuring that members of the community have access to valued social settings and activities, that they are able to meaningfully contribute to those activities that are held, and develop functional capabilities that enable them to participate fully (Moore et al., 2006). In the Engagement Triangle of Campire on understanding the purpose of engagement, it was described that the spatial tool to which identifies the desired outcomes of engagement was based on the overarching objectives of informing decisions, building capacity, and strengthening relationships. Through the engagement triangle, identifying the appropriate tools or techniques in achieving effective community engagement can be determined. By being a triangle, it means that the community engagement can have more than one objective. Based on the Engagement Triangle of Campire, the three spatial tools in Engagement Triangle which are informing decisions, building capacity, and strengthening relationships should be assessed in order to evaluate the effectiveness of an activity or an event. Achieving the three spatial tools only means that the activity is effective in community engagement. Informing decisions means that the Local Government Unit provides an opportunity for the community to contribute to decision-making processes during the planning phase of the event. Building capacity means that the activity educates the community on a specific theme or issue to increase knowledge or change behaviors. Strengthening relationships means that the activity builds new relationships and/or improves relationships with the community. The effectiveness of a program or an event in community engagement will be based on how the community members rate and evaluate every program that is held (Seubert et al., 2018; Parry, 2008).

Considering that the economic impact of festivals itself is not seriously visible, Small (2007), supports that measuring the social impacts of community festivals is enormously important. In the study of Small (2007), entitled "Understanding the Social Impacts of Festival on Communities," results showed that communities sought to provide opportunities for every individual in the community to engage in entertainment, socialization, and that through a festival, communities established social networks. In researching festival cultural contexts within this research topic, Albubo Festival as a tool to enhance community engagement has not been investigated. In the recent study of Muya et al. (2018), light has been shed on Coconut Festival, studying the level of participation and perception of residents in San Pablo City, Laguna. This concept of participation of Filipino Festivals has recently been challenged by Muya et al. (2018), through a study that is focused on demonstrating a model of participation in a Filipino festival. On this note, this research aimed to combine these ideas and to specifically address the following research questions:

1. What is the level of participation of Buguias, Benguet residents in Albubo Festival according to:
a. functional participation
b. passive participation
c. participation by consultation
d. empowered participation?

2. What is the level of effectiveness of Albubo Festival in community engagement along;
a. cultural presentations
b. ukob
c. agricultural trade fair
d. agri-booth competition
e. inter-barangay sports competition?

3. What is the relationship between the level of participation of Buguias residents and the level of effectiveness of Albubo Festival in community engagement? 


\section{Methodology \\ Research design}

In this study, quantitative research was used, specifically the correlational-quantitative method. Gathering numerical data on the three research questions helped to determine the relationship between the level of participation of the residents of Buguias and the level of effectiveness of Albubo Festival in community engagement (Masrul, 2018; Laka \& Suprasto, 2020).

\section{Population and locale of the study}

The study was conducted in the Municipality of Buguias, Benguet, Philippines. The researchers chose respondents who were 18 years old and above because an age limit was observed during the celebration of the activity especially in inter-barangay sports competition. The data from the 2015 Census of Population Authority (2012), reveals that the municipality of Buguias had a total population of 43,627. The total population of Buguias from Authority (2012), was used in Slovin's formula to identify the sample size of the respondents. With the total of 396 sample size, the researchers were able to administer the questionnaire to 396 respondents by sending the link of the Google forms via different existing group chats and personal messages in Messenger application.

\section{Instrumentation}

The researchers used a survey questionnaire as the research instrument for the study. It is composed of two major parts; the first part is titled "Level of Participation of the Buguias Residents", with four items. It is a fully adopted survey questionnaire from the study (Muya et al., 2018). Questions were answered using a four Likert Scale: strongly agree, agree, disagree, and strongly disagree. The second part is a researcher-made questionnaire with fifteen items. Questions were answered using a four Likert Scale: highly effective, moderately effective, slightly effective, not effective. Overall, the survey questionnaire contained nineteen (19) items. The survey questionnaire underwent validity test from one language expert and one expert in the field of development communication. To measure the reliability of the survey questionnaire, pilot testing was done with 40 Buguias residents. Results in the reliability test showed that the level of participation of the Buguias residents in Albubo Festival garnered 0.773, which is acceptable. The reliability test also revealed that the level of effectiveness of Albubo Festival in community engagement is 0.967 , which is excellent.

\section{Data collection procedure}

The researchers sent a request to the respondents through group chats and personal messages in the Messenger application. The researchers allowed the participants to choose, whether to answer the survey questionnaire or not. To know if a respondent would be willing to participate in the research, an invitation to take part in the survey was done before the researchers sent the questionnaire. If respondents agreed to take part in the study, the survey questionnaire were immediately sent to them. After collecting all the data, the researchers then tallied and tabulated them.

\section{Data analysis}

In interpreting the results of the collected data, the researchers used specific statistical tools such as mean to find out the level of participation of Buguias residents and the level of effectiveness of Albubo Festival in community engagement. Furthermore, Pearson's r correlation coefficient was used to investigate the relationship between the level of participation of Buguias residents and the level of effectiveness of Albubo Festival in community engagement (Olowo et al., 2020; Authority \& City, 2019; Uysal \& Gitelson, 1994). 
Results and Discussion

Level of participation of Buguias, Benguet residents in Albubo festival

The table presents the four typologies of participation that are classified as levels of participation. Each level of participation has a mean and its descriptive equivalence.

Table 1

Typologies of participation

\begin{tabular}{clcc}
\hline Level & \multicolumn{1}{c}{ Type of Participation } & Mean & $\begin{array}{c}\text { Descriptive } \\
\text { Equivalence }\end{array}$ \\
\hline 1 & Functional Participation & 3.19 & Agree \\
2 & Passive Participation & 3.31 & Strongly Agree \\
3 & Participation by consultation & 2.62 & Agree \\
4 & Empowered Participation & 1.90 & Disagree \\
Overall Weighted Mean & 2.76 & Agree \\
\hline
\end{tabular}

Table 1 presents the four typologies of participation in a community event. Passive participation, functional participation, participation by consultation, and empowered participation anchored on the Participation Theory of Communication. Overall, the residents strongly agree that the level of participation most of them put into is (level 2) passive participation, with a mean of 3.31. Functional participation (level 1) obtained a mean of 3.19, agree. Participation by consultation (level 3 ) garnered a mean of 2.62, strongly agree. The level 4 , empowered participation, obtained a mean of 1.90, disagree. The level of participation of the residents towards the Albubo Festival obtained an overall weighted mean of 2.76 . This reveals that the residents agreed with the fact that most of them put such level of participation into the festival. The results show that the four levels of participation: functional, passive, participation by consultation, and empowered participation were present during the celebration of Albubo Festival. Identifying the kind and level of participation of Buguias, Benguet residents in Albubo Festival can be a tool to improve the joint effort of the Local Government Unit (LGU), community members, and the facilitators. "Albubo," a Kankana-ey term, means traditional "bayanihan" or helping others or contributing something without expecting something in return. This is one of the basic values that is highlighted in the Albubo Festival and is considered as a community tradition. According to Balderas et al. (2014), assessing the level of participation will serve as an evaluation to identify if an activity or an event held in a community is a failure or a success.

In assessing the level of participation of the Buguias residents in Albubo Festival, functional participation (level 1) obtained a mean of 3.19. It means that the residents of Buguias strongly agree that the community members were informed regarding the program. Further, information dissemination regarding the programs that are held during Albubo Festival, such as cultural presentation, Ukob, agricultural trade fair, agri-booth competition, and interbarangay sports competition is observed. Information dissemination highly affects the participation of the respondents. Informing the residents is enormously important because the more the respondents are informed about the activities, the higher their participation is. More so, being informed only implies that the Local Government Unit (LGU) of Buguias used an effective medium to promote Albubo Festival to the residents. Through print and electronic media such as tarpaulin, newspaper, and social media, specifically Facebook, the level of participation of the residents is high. Therefore, mass communication is observed in the Albubo Festival as it used print and electronic media to transmit and disseminate information to the residents.

The passive participation (level 2) garnered the highest mean of 3.31. It reveals that respondents strongly agree that they are part of the decision-making and implementation of Albubo Festival. It means that the residents show concern in the celebration of Albubo Festival as they are involved in the decision making and its implementation. It implies that they are interested in having joint effort with the Local Government Unit (LGU) and with the organizers of the cultural festival. It reveals how important the festival is to them as they are eager to collaborate and be involved in the improvement and implementation of the festival. Moreover, the more the residents are heard, the greater participation can be attained in the festival as a whole. Staying informed about progress or simply communicating with the decision-makers implies that the activity attained the "Citizen Participation is Citizen Power" as quoted in the study of (Arnstein, 1969).

The participation by consultation (level 3) obtained 2.62, which means that respondents agree that they are consulted by the LGU's or facilitators about the matters involving Albubo Festival. It implies that the LGUs and facilitators acknowledged the importance of the perspectives of the residents about the matters involving Albubo 
Festival. As the residents are consulted by the LGUs and facilitators, the residents may have the willingness to actively participate in Albubo Festival.

The empowered participation (level 4) garnered 1.90. It shows that the residents agree that they are hindered or limited by the facilitators on the celebration of Albubo Festival. It means that they have limitations when joining the celebration of the Festival. Greater participation can be achieved if the facilitators encourage the residents to join in the celebration of the festival. Being mindful of the facilitators of the cultural positions that they have can be a factor in making the residents agree that they are not hindered and limited. Wiltshier \& Clarke (2019), stated that facilitators need to be aware and mindful of their own cultural positions and also of their preferences in connection to the activity or event they are involved with.

Overall, passive participation (level 2) is the most prevalent type of participation among the four typologies. It reveals that the residents strongly agree that they are part of the decision-making and implementation of Albubo Festival. It means that the residents have the willingness to share their thoughts and decisions regarding what to be implemented in the celebration of Albubo Festival. According to Mefalopolus, participation highly affects the decision-making process, which leads to different behavioral and cognitive effects that most likely have a positive effect on the participants of the activity or event. In the study of Balderas et al. (2014), it is revealed that participation of the citizens is a process that offers individuals the opportunities in the community event. It is considered one of the ways to determine how it can influence public decisions and decision-making process. When it comes to decision- making processes, the source of power comes from the participation or power of the citizens. Further, to accomplish the benefits of the objectives, the citizen should first participate (Muya et al., 2018; SeyedAlagheband , 2011).

\section{Effectiveness of Albubo festival in community engagement}

Below are the results of the research question, 'What is the level of effectiveness of Albubo Festival in community engagement?' The table presents the highlights of the activity during the celebration of Albubo Festival as an indicator. Each activity indicates the mean and its descriptive equivalence.

Table 2

Level of effectiveness of Albubo festival in community engagement

Indicator

Cultural Presentations

1. The Local Government Unit (LGU) gives us an opportunity to contribute and make a decision during the planning phase of the cultural presentation.

2. The cultural presentations like tayaw and dance drama are effective in educating the community about their cultural practice.

3. The cultural presentation motivates me as a member of the community to build new relationships and improve relationships within the community.

Overall Mean

Ukob

1. During the planning phase of $u k o b$, LGU regards our suggestions and ideas for the enhancement of the $u k o b$ ceremony.

2. The $u k o b$ /eating together with the use of indigenous table wares such as bakubak as plates, duyo as serving bowls, silap as soup bowls and bakkong as serving spoon taught us to remember our town's indigenous knowledge and practices.

3. The traditional lunch $(u k o b)$ is effective in strengthening personal relationships that build stronger and healthy community culture.

Overall Mean

Agricultural Trade Fair

1. The LGU gives us an opportunity to get involved during the planning phase of agricultural trade fair.

2. The events conducted by the agricultural trade and farmer's congressional committees of the Albubo festival are an effective way to build their skills in different activities like the "comboy" relay contest and potato shooting contest.
Mean Descriptive

Equivalence

2.56 Somewhat Effective

3.45 Highly Effective

3.37 Highly Effective

3.13 Moderately Effective

2.47 Slightly Effective

3.40 Highly Effective

2.48 Slightly Effective

2.78 Moderately Effective

3.61 Highly Effective

3.69 Highly Effective 
3. The seminars conducted by the agricultural trade and farmer's congressional committees are an effective way to build positive practices that lead to the improvement and enhancement of agricultural techniques and strategies by sharing indigenous knowledge and ideas from a community member to another.

Overall Mean

Agri-booth Competition

1. The LGU encourages us to contribute suggestions for the enhancement of the agri-booth competition.

2. The Agri-booth competition is effective in upholding the meaning of Albubo to the community, which is to contribute or help without expecting something in return.

3. As a member of the community, the agri-booth competition is effective in attaining unity and cooperation in a barangay.

Overall Mean

Inter-Barangay Sports Competition

1. The LGU acknowledges and recognizes our recommendation for the planning phase of inter-barangay sports competition.

2. As a member of the community, the inter-barangay sports tournament like volleyball and basketball is effective to the spirit of team building.

3. Inter-barangay sports participants are not taking the event as a competition but rather as a way to build unity effectively among Barrios of Buguias.

Overall Mean

OVERALL WEIGHTED MEAN

2.63 Moderately Effective

3.31 Highly Effective

3.42 Highly Effective

$3.31 \quad$ Highly Effective

2.51 Moderately Effective

3.08 Moderately Effective

3.47 Highly Effective

3.47 Highly Effective

3.43 Highly Effective

3.46 Highly Effective

3.15 Moderately Effective

Table 2 shows cultural presentation had a mean of 3.13, moderately effective. The activity Ukob garnered 2.78, moderately effective. Table 2 also shows that agricultural presentation obtained 3.31, highly effective. Agri-booth competition garnered the mean of 3.08, moderately effective. Inter-barangay sports competition obtained 3.46, highly effective. In assessing the effectiveness in community engagement, the indicators were anchored on the Engagement Triangle (DiClemente et al., 2015). Based on this, each highlight of activities was evaluated based on the three spatial tools in Engagement Triangle. The tools are informing decisions, building capacity, and strengthening relationships. Achieving the three spatial tools only means that the activity is effective in community engagement. Informing decisions means that the Local Government Unit provides an opportunity for the community to contribute to decision-making processes of the activities during the planning phase. Building capacity means that the activity educates the community on a specific theme or issue in order to increase knowledge or change behaviors. Strengthening relationships means that the activity builds new relationships and /or improves relationships with the community. Overall, the level of effectiveness of Albubo festival is moderately effective in community engagement, obtaining a mean of 3.15 .

\section{Level of effectiveness of Albubo festival in community engagement along cultural presentation}

Results show that informing decisions as one of the spatial tools on Engagement Triangle in conducting cultural presentation is slightly effective in community engagement, which obtained the lowest mean of 2.56 . This means that cultural presentations such as tayaw and dance drama are effective to a limited extent in community engagement. The limited opportunity provided by the Local Government Unit (LGU) for residents to contribute and make a decision during the planning phase of the cultural presentation may create a contradiction between the residents and the LGUs when it comes to their the way of thinking. Furthermore, the expectation of the residents may not be met in the actual implementation during the celebration of Albubo Festival because the residents are not that involved during the planning phase. For this reason, it is vital to consider the residents' decisions during the planning phase because a cultural festival like Albubo defines the people within and the center of it is the culture they have. A festival provides an enormous opportunity to observe the communicative system of the culture conveyed through semiotically complex performance events (Cornwall, 2008).

In conducting cultural presentations, the results show that the most effective spatial tool in community engagement is building capacity, having a mean of 3.45, with a descriptive equivalence of highly effective. For the respondents, cultural presentations like tayaw and dance drama are highly effective in educating the community about the cultural practices that they have. Cultural presentations have a tremendous positive impact to help all members of the community inculcate the cultural practices that they have. They perform and learn, at the same time. 
It means the more learnings about the cultural presentations, the higher the effectiveness of the activity is in community engagement.

Overall, the level of effectiveness of Albubo Festival in community engagement along with cultural presentation is moderately effective obtaining a 3.31 mean. It implies that the three spatial tools of Engagement Triangle are present and have been achieved adequately. With this, effective community engagement is attained moderately. It implies that the more often the LGU provides an opportunity to the community to join in decision-making processes during the planning phase of cultural presentation, the higher the effectiveness of the activity is in community engagement.

\section{Level of effectiveness of Albubo festival in community engagement along Ukob}

In conducting the activity $u k o b$, the results show that informing decisions as one of the spatial tools in Engagement Triangle has the lowest mean of 2.47 , with a descriptive equivalence of slightly effective. This means that during the planning phase of $u k o b$, LGU considered the suggestions and ideas for the betterment of the $u k o b$ ceremony to a limited extent. The limited opportunity given by the LGU to the residents during the planning phase of $u k o b$ may create a contradiction because the perspectives of the LGU in improving the activity during the planning phase may differ from the ideas of the residents. This may result in not meeting the expectations of the residents in the actual implementation of the activity as they are not involved in the decision-making processes during the planning phase.

Obtaining the highest mean of 3.40 with a descriptive equivalence of highly effective, 'building capacity' is the most effective spatial tool in $u k o b$. Ukob or eating together with the use of indigenous table wares such as bakubak as plates, duyo as serving bowls, silap as soup bowls, and bakkong as serving spoon taught the residents to remember the town's indigenous knowledge and practices. This is seen to be highly effective in community engagement. It is because it increases the indigenous knowledge among the residents. Through $u k o b$, cultural practices can be maintained as this is learned and practiced in the celebration of Albubo Festival.

Overall, the level of effectiveness of Albubo Festival along $u k o b$ obtained a mean of 2.78 which means that it is moderately effective in community engagement. It implies that the three spatial tools are present and have been achieved moderately. The results show that it obtains the mean of 2.78 which indicates that informing decisions and strengthening relationships are slightly effective in community engagement despite the high level of effectiveness of building capacity. It is not just the limitations of the residents in decision-making processes during the planning phase in the activity ukob, but also the minimal effectiveness of the traditional lunch (ukob) in strengthening personal relationships of the residents towards the culture. The residents do not just obtain indigenous knowledge during $u k o b$, but also gain a sense of community to the cultural practices they have.

\section{Level of effectiveness of Albubo festival in community engagement along agricultural trade fair}

In conducting agricultural trade fair, the spatial tool, strengthening relationship, garnered the lowest mean of 2.63, having a descriptive equivalence of moderately effective. To some extent, seminars conducted by the agricultural trade and farmer's congressional committees are an effective way to build positive practices. These lead to the improvement of agricultural techniques and strategies by sharing indigenous knowledge and ideas from a community member to another. Enhancing the spatial tool 'strengthening relationship' makes the learning interesting during seminars. The more the residents strengthen their relationship in agricultural trade fair, the higher its effectiveness in community engagement. With this, the residents are not just learning but can also make positive practices that lead to the improvement of the agricultural strategies using indigenous farming methods. Together, they can make "bayanihan" in planting the agricultural products more effective.

Getting the highest mean of 3.69 with a descriptive equivalence of highly effective, the spatial tool, building capacity, in the Engagement Triangle is the most effective tool in community engagement. Undoubtedly, agricultural trade fair educates the residents through seminars that are conducted. To add, activities like the "comboy" relay contest and potato shooting contest are an effective way to build farming skills. These are conducted by the agricultural trade and farmers' congressional committees. Through agricultural trade fair, the community tradition

albubo or bayanihan can be attained effectively as the "comboy" relay contest alone defines the true meaning of albubo. "Comboy" or convoy in English is a term that pertains to helping one another in doing agricultural activities or farming.

Overall, the level of effectiveness of Albubo Festival in community engagement along agricultural trade fair garnered 3.31, having a descriptive equivalence of highly effective. It implies that the three spatial tools were present in the activity, agricultural trade fair. However, one spatial tool that needs to be enhanced is strengthening 
relationship, which has the lowest mean among the three spatial tools. Strengthening the relationship among the residents in this activity fosters the indigenous knowledge and ideas from a community member to another about agricultural techniques. It is pivotal to give the residents an opportunity to participate in the planning phase of Albubo Festival's agri-trade fair and allow them to develop their skills in different activities like "comboy" relay contest and potato shooting contest. A case study of National Young Farmers Coalition of America noted that promoting agriculture in a community is a good way to elevate local food and farms. Having a community engagement in agriculture helps to build relationships, identify the needs of the community, and accomplish common goals.

\section{Level of effectiveness of Albubo festival in community engagement along agri-booth competition}

The results show that strengthening relationship garnered the lowest mean of 2.51, with a descriptive equivalence of moderately effective, in conducting agri-booth competition. To some extent, agri-booth competition is effective in attaining unity and cooperation in a barangay. Enhancing this spatial tool strengthens the community tradition "albubo or bayanihan". Having unity and cooperation means that the tradition of the community is achieved. Obtaining the highest mean of 3.42, with a descriptive equivalence of highly effective, the spatial tool 'informing decisions' is more manifested in agri-booth competition. It implies that the LGU encourages the residents to contribute suggestions for the betterment of the agri-booth competition. Having a successful event means that the LGU and the residents help each other in the decision-making processes during the planning phase for the improvement of the activity

Overall, the effectiveness of Albubo Festival in community engagement along agri-booth competition obtained 3.08 , with a descriptive equivalence of moderately effective. It implies that the three spatial tools are present in agribooth competition. Conducting competitions is one of the strategies in villages in order to improve the people's welfare in a sustainable manner. Also, development in a participatory way by involving community members will foster a sense of community empathy (Setyobakti, 2021). Through engaging in agri-booth competitions, there is a possibility that community members in every barangay will foster not only the local products they displayed during agri-booth competition but also a sense of empathy for others.

\section{Level of effectiveness of Albubo festival in community engagement along inter-barangay sports competition}

Among all the highlights of activities, 'inter- barangay sports competition' has the highest level of effectiveness. It implies that the three spatial tools are present in inter-barangay sports competition. 'Strengthening relationship' has a mean of 3.43, with a descriptive equivalence of highly effective and 'informing decisions' and 'building capacity' obtained a mean of 3.37, with a descriptive equivalence of highly effective. The Department of Local Government in Western Australia supports that sports help the community be united and be strengthened. Also, it develops strong social bonds. Garnering the highest mean reveals that the inter-barangay sports competition has an enormous role in maintaining a cohesive community in the celebration of Albubo Festival. The more the Local Government Unit (LGU) supports inter-barangay sports competition, the greater community engagement could take place among the residents.

The relationship between the level of participation of Buguias residents in Albubo festival and its effectiveness in community engagement

Table 3

The relationship between the level of participation of Buguias residents in Albubo festival and its effectiveness in community engagement

\begin{tabular}{|c|c|c|c|c|c|c|c|c|}
\hline \multirow{3}{*}{ Indicator } & \multicolumn{8}{|c|}{ Type of Participation } \\
\hline & \multicolumn{2}{|c|}{$\begin{array}{l}\text { Functional } \\
\text { Participation }\end{array}$} & \multicolumn{2}{|c|}{$\begin{array}{c}\text { Passive } \\
\text { Participation }\end{array}$} & \multicolumn{2}{|c|}{$\begin{array}{l}\text { Participation by } \\
\text { consultation }\end{array}$} & \multicolumn{2}{|c|}{$\begin{array}{l}\text { Empowered } \\
\text { Participation }\end{array}$} \\
\hline & $\mathrm{r}$ & $\mathrm{p}$-value & $\mathrm{r}$ & $\begin{array}{c}\mathrm{p}- \\
\text { value }\end{array}$ & $\mathrm{r}$ & $\mathrm{p}$-value & $\mathrm{r}$ & $\begin{array}{c}\mathrm{p}- \\
\text { value }\end{array}$ \\
\hline Cultural presentation & $0.146^{* *}$ & 0.004 & 0.096 & 0.057 & $0.262 * *$ & 0.000 & $0.206^{* *}$ & 0.000 \\
\hline Ukob & $0.123 *$ & 0.014 & $-0.104 *$ & 0.039 & $0.193 * *$ & 0.000 & $0.178^{* *}$ & 0.000 \\
\hline Agricultural trade fair & 0.011 & 0.824 & $0.158 * *$ & 0.002 & $0.103 *$ & 0.042 & 0.029 & 0.564 \\
\hline Agri-booth competition & -0.077 & 0.129 & $-0.114 *$ & 0.024 & 0.005 & 0.929 & 0.020 & 0.697 \\
\hline
\end{tabular}




\begin{tabular}{lllllllll}
\hline $\begin{array}{l}\text { Inter-barangay sports } \\
\text { competition }\end{array}$ & -0.064 & 0.204 & -0.017 & 0.730 & $0.138^{* *}$ & -0.006 & $-0.106^{*}$ & 0.036 \\
\hline
\end{tabular}

The activity $u k o b$ has a very weak correlation to functional participation with a 0.01 significance level, precisely with 0.123 correlation. Also, it has a negligible correlation to passive participation with a level of significance 0.05 , specifically with -0.104 correlation. The activity 'agricultural trade fair' has a very weak correlation to participation by consultation having 0.05 level of significance, precisely having 0.158 correlation. It has a negligible correlation to participation by consultation with a 0.01 level of significance, specifically having 0.103 correlation. Moreover, the activity 'agri-booth competition' has a negligible correlation to passive participation with 0.01 level of significance and of -0.114 correlation, to be exact. On another note, the activity 'inter-barangay sports competition' has a negligible correlation to participation by consultation and empowered participation with 0.01 significant level. Specifically, it has -0.064 correlation in the functional participation and 0.138 in the participation by consultation.

Table 3 presents the insignificant relationship between the level of participation of Buguias residents in Abubo Festival and its effectiveness in community engagement. The results suggest that there is no enough evidence to claim that level of participation is related to the level of effectiveness of Albubo Festival. It implies that the level of participation of the residents does not influence the level of effectiveness of Albubo Festival in community engagement or vice versa. However, Marino-Puertas (2017), stated that engagement is the key to attain good participation. In contrast to the result of the study, Marino-Puertas (2017), also revealed that the participation of the residents and the effective community engagement go hand in hand. The effectiveness of cultural presentation in community engagement has a very weak correlation to functional participation. It implies that the effectiveness of cultural presentation in community engagement has a very weak influence in the participation of the residents, particularly in being informed about the programs and regulations. This means that the level of participation of residents in Buguias, specifically the functional participation, does not go hand in hand with the level of effectiveness of Albubo Festival in community engagement along cultural presentation.

Further, its effectiveness in community engagement has a weak correlation to participation by consultation. It means that the effectiveness of cultural presentation in community engagement has a weak influence to the participation of the residents, particularly to being consulted by the LGU or facilitators about matters involving the activity. In addition, it shows that its effectiveness in community engagement has a very weak correlation to empowered participation. Generally, this means that the level of participation of Buguias residents particularly functional participation, participation by consultation, and empowered participation does not go hand in hand to the level effectiveness of Albubo Festival in community engagement along cultural presentation. The effectiveness of $u k o b$ in community engagement has a very weak correlation to functional participation. It shows that effectiveness of $u k o b$ in community engagement has a very weak influence on the participation of the residents. This is in being informed about the programs and regulation of the activity, to be accurate. Additionally, its effectiveness in community engagement has a negligible correlation to passive participation. It implies that $u k o b$, in its effectiveness in community engagement, has an insignificant influence on the participation of the residents in decision-making and implementation of the activity. In general, the level of participation of the Buguias residents, specifically functional and passive participation, is not interdependent with the level of effectiveness of Albubo Festival in community engagement along the activity $u k o b$.

The effectiveness of agricultural trade fair in community engagement has a negligible correlation to passive participation. It means that the effectiveness of agricultural trade fair in community engagement has an insignificant correlation to the participation of the residents in the decision-making and its implementation. Moreover, its effectiveness in community engagement has a very weak correlation to participation by consultation. It reveals that the effectiveness of agricultural trade fair in community engagement has a very weak influence on the participation of the residents, particularly when these people are being consulted by the LGU's or facilitators about matters involving the activity. Basically, the level of participation of the Buguias residents, specifically passive participation and participation by consultation, has nothing to do with the level of effectiveness of Albubo Festival in community engagement along agricultural trade fair. The effectiveness of agri-booth competition in community engagement has a negligible correlation to passive participation. It only implies that the effectiveness of agri-booth competition in community engagement has insignificantly influenced the participation of the residents in the decision-making and implementation of the activity. In general, the level of participation of Buguias residents particularly passive participation is not interdependent to the level of effectiveness of Albubo Festival in community engagement along agri-booth competition.

The effectiveness of inter-barangay sports competition in community engagement has a negligible correlation to participation by consultation. It means that the effectiveness of inter-barangay sports competition in community engagement has an insignificant influence on the participation of residents particularly in being consulted by the 
LGU's or facilitators about the matters involving the activity. Furthermore, its effectiveness in community engagement has a negligible correlation to empowered participation. It signifies that the effectiveness of interbarangay sports competition has insignificantly influenced the participation of the residents in terms of being hindered or limited by the facilitators along the celebration of the activity. The level of participation of Buguias residents, specifically participation by consultation, does not impact the level of effectiveness of Albubo festival in community engagement along inter-barangay sports competition.

Overall, the results reveal that there is an insignificant relationship between the level of participation of Buguias residents in Albubo Festival and its effectiveness in community engagement. The results suggest that there is no enough evidence to claim that level of participation is related to the level of effectiveness of Albubo Festival. This shows that the two factors do not influence each other. Thus, passive participation, functional participation, participation by consultation, and empowered participation have an insignificant relationship or are not related to the effectiveness of the activities such as cultural presentations, ukob, agricultural trade fair, agri-booth competition and inter-barangay sports competition held during the celebration of Albubo Festival.

\section{Conclusion}

The researchers found that the four different typologies of Mefalopolus (2003), are present in the celebration of Albubo Festival. Moreover, passive participation (level 2) is the most prevalent among the typologies. This reveals that the respondents strongly agree that they are part of the decision-making and implementation of the Albubo Festival. It implies that they are interested to have joint effort with the Local Government Unit (LGU) and to the organizers of the cultural festival. The results also show that empowered participation is not much observed in the celebration of Albubo Festival. The respondents stated that they are hindered or limited by the facilitators during the celebration. The respondents perceive that they are not empowered to take part in the cultural festival. Greater participation can be achieved if the facilitators encourage the residents to join in the celebration.

Based on the results of the study, the level of effectiveness of Albubo Festival in community engagement along cultural presentations is moderately effective, obtaining a mean of 3.31. Along Ukob, the level of effectiveness in community engagement is moderately effective with a 2.78 mean. Along agricultural trade fair, the level of effectiveness in community engagement is highly effective with a mean of 3.31 . In addition, the level of effectiveness of Albubo Festival in community engagement along agri-booth competition is moderately effective with a mean of 3.08. Along inter-barangay sports competition, the level of effectiveness in community engagement is highly effective with a mean of 3.37. Moreover, findings of the study revealed that the tool to enhance community engagement in Albubo Festival along cultural presentation is building capacity. It implies that cultural presentations like tayaw and dance drama are highly effective in educating the community about the cultural practices that they have. Along $u k o b$, the tool to enhance community engagement is building capacity. During $u k o b$, eating together with the use of indigenous table wares such as bakubak as plates, duyo as serving bowls, silap as soup bowls and bakkong as serving spoon has taught the residents to remember the town's indigenous knowledge and practices. It implies that this is highly effective in community engagement because it deepens indigenous knowledge among the residents. Furthermore, the tool to enhance community engagement in agricultural trade fair is building capacity. The activities like the "comboy" relay contest and potato shooting contest are highly effective in building the farming skills of the residents. Along agri-booth competition, the tool to enhance community engagement is informing decisions. It implies that the LGU encourages the residents to contribute suggestions for the betterment of the agribooth competition. The more the LGU consults the residents in the decision-making processes during the planning phase, the higher the effectiveness of agri-booth competition in community engagement. Along inter-barangay sports competition, the tools in enhancing community engagement are informing decisions and building capacity. It implies that the more residents are informed about inter-barangay sports competition, the higher the community engagement. Furthermore, the activity educated the community about unity in sports competition.

The results also reveal that there is an insignificant relationship between the level of participation of Buguias residents on Albubo Festival and the effectiveness of Albubo Festival in community engagement. It implies that there is no enough evidence to claim that level of participation is related to the level of effectiveness of Albubo Festival. This result is opposite to the study of Muya et al. (2018), a model of participation in Filipino festival. It reveals that the most prevalent typology in the celebration of the Coconut Festival is empowered participation (level 4), while this study showed that passive participation (level 2) is the most prevalent in Albubo Festival. The Coconut Festival is a week-long event that includes a variety of programs to promote unity and participation among San Pablo City residents, whereas the Albubo Festival is a celebration of the town's indigenous knowledge systems and practices among Buguias, Benguet residents. 


\section{References}

Arnstein, S. R. (1969). A ladder of citizen participation. Journal of the American Institute of planners, 35(4), 216224.

Authority, N. T. (2012). Management Information System. Issue 43rd, 91.

Authority, P. S., \& City, Q. (2019). First Semester 2018 Official Poverty Statistics of the Philippines. Quezon City: Philippine Statistics Authority.

Awas, F. D. (2009). Staged Bendian as a Medium of Community Dialogue and Action for Development and Cultural Integrity in Contemporary Kabayan. Open University, Benguet State University

Balderas, B., Gareza, J., Pineda, P., \& Opena, A. (2014). Factors Associated with the Level of Participation of Stakeholders in Barangay San Juan Adopt-a-River Project. Lyceum of the Philippines- Laguna.

Choi, S. H., Imon, S. S., \& Couto, U. (2020). Negotiating with authenticity to ensure sustainability of traditional cultural festivals: Residents' perspectives about Macao's drunken dragon festival. Sustainability, $12(3), 885$.

Cornwall, A. (2008). Unpacking 'Participation': models, meanings and practices. Community development journal, 43(3), 269-283.

DiClemente, R. J., Salazar, L. F., \& Crosby, R. A. (2015). Community-based participatory research in the context of health promotion. Research methods in health promotion, 313.

Kim, J., Chung, H. K., \& Chae, C. (2003). Association of porcine circovirus 2 with porcine respiratory disease complex. The Veterinary Journal, 166(3), 251-256.

Lacaden, A. (2017). Buguias launches Albubo Festival Baguio. Midland Courier Website News Article.

Laing, J. (2018). Festival and event tourism research: Current and future perspectives. Tourism management perspectives, $25,165-168$. https://doi.org/10.1016/j.tmp.2017.11.024

Laka, M. D. L. M. W., \& Suprasto, H. B. (2020). Accountability, information technology and village performance. International Research Journal of Management, IT and Social Sciences, 7(2), 71-78. https://doi.org/10.21744/irjmis.v7n2.874

Lee, C. K., Lee, Y. K., \& Wicks, B. E. (2004). Segmentation of festival motivation by nationality and satisfaction. Tourism management, 25(1), 61-70. https://doi.org/10.1016/S0261-5177(03)00060-8

Lee, K. Y., \& Lee, H. (2019). Traditional costume experience at a cultural heritage festival. Tourism Management Perspectives, 32, 100555. https://doi.org/10.1016/j.tmp.2019.100555

Makdisi, G., Takeuchi, T., Rodriguez, J., Rucinski, J., \& Wise, L. (2011). How we select our residents—a survey of selection criteria in general surgery residents. Journal of Surgical Education,68(1), 67-72. https://doi.org/10.1016/j.jsurg.2010.10.003

Marino-Puertas, L., Goulas, T., \& Gomis-Rüth, F. X. (2017). Matrix metalloproteinases outside vertebrates. Biochimica et Biophysica Acta (BBA)-Molecular Cell Research, 1864(11), 2026-2035.

Masrul, .-. (2018). Communications interaction of mining company to community in corporate social responsibility program implementation. International Research Journal of Management, IT and Social Sciences, 6(1), $42-54$. https://doi.org/10.21744/irjmis.v6n1.482

Minter, R. M., Gruppen, L. D., Napolitano, K. S., \& Gauger, P. G. (2005). Gender differences in the self-assessment of surgical residents. The American journal of surgery, 189(6), 647-650. https://doi.org/10.1016/j.amjsurg.2004.11.035

Moore, D., Shannon, C., Brown, D. J., Voelker, G. M., \& Savage, S. (2006). Inferring internet denial-of-service activity. ACM Transactions on Computer Systems (TOCS), 24(2), 115-139.

Moser, S. C., \& Pike, C. (2015). Community engagement on adaptation: Meeting a growing capacity need. Urban Climate, 14, 111-115. https://doi.org/10.1016/j.uclim.2015.06.006

Muya, G., Ladanga, J. L., \& Padrigalan, M. A. Y. N. (2018). MODEL OF PARTICIPATION IN A FILIPINO FESTIVAL. Lyceum of the Philippines-Journal of Arts and Sciences, 3(1), 1-1.

Olowo, B. F., Fashiku, C. O., Adebakin, A. B., \& Ajadi, O. T. (2020). Social Media: A Modern Tool to Enhance Communication Skills of the Secondary School Principals in Ekiti State. International Journal of Education and Development using Information and Communication Technology, 16(2), 97-108.

O'Sullivan, D., \& Jackson, M. J. (2002). Festival tourism: a contributor to sustainable local economic development?. Journal of sustainable tourism, 10(4), 325-342.

Parry, R. (2008). Are interventions to enhance communication performance in allied health professionals effective, and how should they be delivered? Direct and indirect evidence. Patient education and counseling, 73(2), 186195. https://doi.org/10.1016/j.pec.2008.05.029 
Ryan, B., Johnston, K. A., Taylor, M., \& McAndrew, R. (2020). Community engagement for disaster preparedness: A systematic literature review. International journal of disaster risk reduction, 49, 101655. https://doi.org/10.1016/j.ijdrr.2020.101655

Seubert, L. J., Whitelaw, K., Hattingh, L., Watson, M. C., \& Clifford, R. M. (2018). Interventions to enhance effective communication during over-the-counter consultations in the community pharmacy setting: A systematic review. Research in Social and Administrative Pharmacy, 14(11), 979-988. https://doi.org/10.1016/j.sapharm.2017.12.001

Seyed-Alagheband, S. A., Ghomi, S. F., \& Zandieh, M. (2011). A simulated annealing algorithm for balancing the assembly line type II problem with sequence-dependent setup times between tasks. International Journal of Production Research, 49(3), 805-825.

Shultz, L. (2015). Decolonizing UNESCO's post-2015 education agenda: global social justice and a view from UNDRIP.

Small, K. E. (2007). Understanding the social impacts of festivals on communities.

Stankova, M., \& Vassenska, I. (2015). Raising cultural awareness of local traditions through festival tourism. Tourism \& Management Studies, 11(1), 120-127.

Uysal, M., \& Gitelson, R. (1994). Assessment of economic impacts: Festivals and special events. Festival Management and Event Tourism, 2(1), 3-9.

Wiltshier, P., \& Clarke, A. (2019). Community-based tourism in the developing world: Community learning, development \& enterprise. Routledge.

Zou, Y., Meng, F., Bi, J., \& Zhang, Q. (2021). Evaluating sustainability of cultural festival tourism: From the perspective of ecological niche. Journal of Hospitality and Tourism Management, 48, 191-199. https://doi.org/10.1016/j.jhtm.2021.06.009 